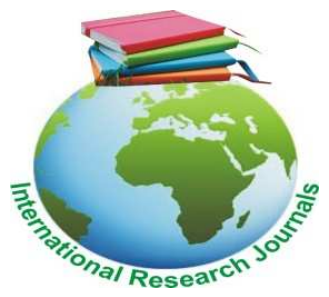

Educational Research (ISSN: 2141-5161) Vol. 9(2) pp. 035-041, March, 2018

Available online@ http://www.interesjournals.org/ER

DOI: http:/dx.doi.org/10.14303/er.2017.217

Copyright (C) 2018 International Research Journals

\title{
Review
}

\section{An empirical analysis of student's perception towards group work - a Middle East perspective}

\author{
${ }^{1}$ Muhammed Refeque, ${ }^{2}$ Kavitha Balakrishnan ${ }^{*}$ Nihan Kutahnecioglu Inan ${ }^{3}$ Madhubala Bava \\ Harji
}

Faculty of Applied Communication Multimedia University Jalan Ayer Keroh Lama Bukit Beruang 75450 Melaka Malaysia ${ }^{*}$ Corresponding Author's Email: kavitha.balakrishnan@mmu.edu.my

\begin{abstract}
Group works have become an integral component of modern education system. The focus of this study is to explore the students' perception of group works. Based on a pilot study with 64 students and subsequent study with $\mathbf{2 7 4}$ participants, this research provides a holistic reading on group works from students' perspectives. The study analyses relative preference of students between individual and group assignments, advantages and disadvantages of group works and the strategies followed by the students in the process. The study also explores students' perception of free riding, peer evaluation and practical issues that teachers need to consider in designing group works. Analyses are conducted to capture the differences in perception based on the gender, academic performance and year of study of the participants.
\end{abstract}

Keywords: Group assessment, student perception, free riding, social loafing, peer evaluation, individual contribution

\section{INTRODUCTION}

Group works have recently become an integral component of present day education system (Gamson, 1994; Morris and Hayes, 1997; Elliott, 2005; Friedman and Maher, 2008; Hall and Buzwell, 2013) thanks to the pedagogical advancements related to constructivist and active learning approaches. The curriculum design in the educational institutions today give due importance for encouraging collaborative learning among students as it would contribute to their overall development. When the students are made to work with peers on certain projects, assignments or case studies, their soft skills and transferable skills get improved and advanced learning skills is enabled (Ruel et al., 2003; Gibbs, 2009).

Research findings have shown that group works promote cognitive and affective growth in students (Smith and Bath, 2006), and the attributes obtained from the group works can be applied in the workplace settings. As the employers require the graduates to exhibit teamwork skills, the educational institutions provide the opportunities for students to work in small groups, so that the students become competent team players (Pfaff and Huddleston, 2003; Maiden and Perry, 2011). Hence, the current need of the workplace has triggered inclusion of group works in curriculum design in educational institutions (Colbeck et al., 2000; Aggarwal and O'Brien, 2008).

There are many researches carried out on group works (Gibbs, 2009; Bentley and Warwick, 2013) covering various aspects. Some of the studies look into the potential benefits, while others study pitfalls associated with it (Burke, 2011) such as social loafing (Harkins, et al., 1980; Williams et al., 1981; Brook sand Ammons, 2003; Piezon and Donaldson, 2005), free riding (Gibbs, 2009; Mc Ardle et al., 2005; Kerr and Bruun, 1983) and sucker effects (Kerr, 1983; Robbins, 1995; Abele and Diehl, 2008). Few researches are also available analysing the student perception (Garvin et al., 1995; Knight, 2004; Amato and Amato, 2005; So and Brush, 2008; Bentley and Warwick, 2013) of group assignment based on different criteria. However, there is still need for a holistic research analysing students' perception especially in the context of Middle East.

The current study analyses the students' perception of group a ssignment covering various areas like relative 
preference of students between group and individual assignments, their perception of potential benefits and pitfalls, strategies employed by them to get tasks done by peers, transferable skills of group works and the communication channels widely used to facilitate the collaboration. In addition, the study also explores the student perception of differentiating the grades based on the individual contribution to curtail the problems of free riding and social loafing.

\section{Advantages of group works}

Group works are important elements of student learning and assessment, and have great potential in enhancing student learning experience. Studies have shown group work accelerates student performance (Johnson, 1991) and leads to acquisition of various skills (Knight, 2004).

There are several research studies (Webb, 1995; Butcher et al., 1995; Garvin et al., 1995; Hayes, Lethbridge and Port, 2003; Cheng and Warren, 2000; Alden, 2011) discussing the benefits inherent in the group works. The literature mainly focuses on the advantages, and the most widely discussed points include the potential of group works in promoting collaborative learning, teamwork and cooperation. Group works also provide opportunities for learning from each other through co-construction of knowledge, generating many ideas, and facilitating higher and deeper level of learning. Group works also ensure the achievement of larger outcomes which will be impossible or comparatively difficult otherwise. In addition, various transferable skills that accrue group works include capacity to motivate and lead the team, overcome the challenges, meet the deadlines, improve problem solving skills, and after all, being engaged in the group works gradually prepare the students to meet the requirements of the workplace. Thus, engagement in the collaborative learning through group works results in acquisition of various cognitive, affective and transferable skills.

\section{Disadvantages of group works}

As mentioned above, group works have great potential in enabling collaboration and improving soft skill development in students. However, group assessments have always been a subject of critical discourse especially with regard to free riders' problem and social loafing, which impede potential benefits of group works (Gibbs, 2009).

Free riding is an academic failure inherent in the group works (Aggarwal and O'Brien, 2008) where the members of a group are awarded same grades irrespective of their individual contribution. Failure to capture individual contribution and to award deserving students accordingly leads to an unfair mark distribution (Kennedy, 2005; Börjesson et al., 2006).
Free riding, which is the result of someone's attempt to freely enjoy the benefits of others' efforts (Stroebe et al., 1996), benefits students who contribute less or nothing and discourage the students who really work. This is best explained by (Morris and Hayes, 1997) as free riding is the attempt of non-performing group member to reap the benefits of a group work without having any personal contribution.

Studies have also analysed the phenomenon from a psychological perspective and considered free riding from students' perception as "dispensable" efforts for the successful accomplishment of group work (McArdle et al., 2005; Kerr and Bruun, 1983). Under such circumstances, free riding becomes detrimental to the whole purpose of group assessments, and the very idea of collaboration is challenged. As it leads to an unfair and undeserved reward for non-performers, it also has adverse effect on the morale and spirit of hardworking, deserving and serious students. Students, who have the potential and willingness to work, are dangerously demotivated as they feel they are misused or exploited by their peers. This phenomenon, which is termed as "sucker effect" by Kerr (1983), reduces the inputs of potential students (Latané et al., 1979) as they do not want to be seen as someone who is doing all the work for their peers (Mulvey and Kein, 1998).

The academic literature related to free riders' problems also provide a discussion on social loafing and reduction of individual efforts during group works or assignments (Harkins et al., 1980; Williams et al., 1981; Brooks and Ammons, 2003; Piezon and Donaldson, 2005). As (Karau and Williams 1995) mentioned, social loafing denotes the fact that collaborative work, compared to individual tasks, reduces the motivation and efforts of group members.

Other disadvantages of group assignment as per the existing literature (Beebe and Masterson, 2003; Waite et al., 2004; Hansen, 2006; Li and Campbell, 2008; Burke, 2011) include non-cooperation, negligence, unnecessary delays and heavy dependence on others by group members. Thus, without proper management, the group tasks won't achieve the intended outcomes, and students will experience lack of enthusiasm in collaboration during the learning process.

\section{Capturing individual contribution}

Overcoming the problems of awarding the same grades for the group members without considering the individual contribution is very challenging (Cheng and Warren, 2000; Wilkins and Law head, 2000). If the problem is left unattended, the whole purpose of group assignment is at risk and students gradually would show unwillingness and detest it. Absence of a fairer and consistent marking scheme for group works can lead to several related problems. Consistency can be ensured if the differences in the accomplishment of outcomes are reflected in the 
marks awarded among groups to groups and individuals to individuals. Similarly, the fairness in marking will be questioned if the marks are awarded only for the final product regardless of the contribution of each member (Hayes et al., 2003). Many research findings assert that the grades in a group projects need to be awarded based on the individual contribution in order to minimise the problems of free riding and social loafing (Kruck and Reif, 2001).

There are many methods explored by academicians to single out the individual contribution in a group work, and most widely used means being the peer assessment (Mathews, 1994; Garvin et al., 1995; Butcher et al., 1995; Topping, 1998; Chenga and Warren, 2000; Kennedy, 2005; Fellenz, 2006; Raban and Litchfield, 2007; Friedman and Maher, 2008; Zundert et al., 2010; Alden, 2011). Substantiating this argument, (Elliot, 2005) has rightly mentioned that the peer assessment is one of the means for overcoming the problems of free riding.

\section{METHODOLOGY}

Based on the literature review, a questionnaire was designed to conduct a pilot study with an objective of capturing the general perception of students on areas like relative preference between individual and group assignments, their perceptions on the advantages and disadvantages of the group assignment, strategies used to encourage participation among group members, and opinions related to the marks distribution.

The questionnaire was then modified in the light of the comments from the pilot study. The phase two questionnaire included more Likert style questions that were designed based on the most commonly repeated responses from the pilot study. It also included questions to analyse the results based on the semesters the students study, their gender and the grades they scored. Few additional questions were also included to get the student feedback on the problem of free riding, and perception of peer-evaluation which can be used to differentiate the marks in the group work.

Various studies such as (Webb, 1995; Butcher et al., 1995; Garvin et al., 1995; Hayes et al., 2003; Cheng and Warren 2000; Alden 2011; Ruel et al., 2003; Gibbs, 2009; Beebe and Masterson 2003); Waite et al., 2004; Hansen, 2006; Li and Campbell 2008; Burke, 2011) are taken into consideration while developing the survey questionnaire for this study.

\section{Sample of the study}

A total of 64 participants were involved in the pilot study; 49 females and 15 males. In the second study, there were 274 respondents; $25 \%$ males and $75 \%$ females from Oman. The participants were categorised broadly into two levels based on their levels: Diploma and Undergraduate Degree. $74.8 \%$ of the participants were from Diploma level and $25.2 \%$ from Undergraduate Degree level.

\section{Analysis and findings}

\section{Students' preference of group and individual assignments}

Data shows a slight difference in terms of participants' preference between individual assignment (52\%) and group assignment (48\%), and this finding is very much in line with that of Bentley and Warwick (2013) which is 51 and 49 per cent respectively. Further analysis conducted to capture the possible difference between Diploma and Degree students in their preference shows that the number of students preferring group assignment is more among Diploma level students (53\% of participants) compared to that of Degree students (47\%). It implies that the students in higher semesters prefer individual assignment. However, the difference is not significant ( $p$ value $=0.469$ ). Similarly, there is no significant difference in the preference based on the gender of participants.

The analysis was made to find out the relationship between the preference of students and their academic performance. The students were categorised into two groups based on their CGPA. Students with CGPA of 1 to 3 fall in the first category and those with more than 3 (out of 4) fall under the second category. The results show that the students with higher CGPA prefers individual assignment more (65.3\%), whereas the students with lower CGPA prefers group assignment (56.8\%). This difference is found to be significant with a $p$ value of 0.005 .

\section{Advantages and disadvantages of group works}

In the pilot study, most repeated advantages of group assignment were 1) developing generic skills, 2) developing teamwork skills and enabling cooperation, 3) developing communication skills, and 4) generating more ideas through co-construction of knowledge. This is in line with the available literature and is further supported with the second study. The results in the second study show that $76.6 \%$ of the students agree that the group works enhance their generic skills. $72.6 \%$ of students agree that group works develop teamwork skills and enables cooperation.

Furthermore, it is interesting to note that the majority of participants (81.4\%) agree that group work enhances communication skills and almost an equal percentage of respondents (83.7\%) agree that the involvement in the group assignments leads to generation of ideas. The table below summarises the responses on the advantages of group works. 
Table 1: Responses to the questions related to advantages of group works

\begin{tabular}{lcccc}
\hline \multirow{2}{*}{ Responses } & \multicolumn{3}{c}{ Percentage (\%) } \\
\cline { 2 - 4 } & Generic skills & $\begin{array}{c}\text { Teamwork skills } \\
\text { and cooperation }\end{array}$ & $\begin{array}{c}\text { Communication } \\
\text { skills }\end{array}$ & Generation of many ideas \\
\hline Strongly agree & 30.8 & 16.7 & 30.3 & 30.8 \\
Agree & 52.9 & 55.9 & 51.1 & 52.9 \\
Neither agree nor disagree & 11.0 & 19.4 & 13.6 & 11.0 \\
Disagree & 1.9 & 3.8 & 1.1 & 1.9 \\
Strongly disagree & 3.4 & 4.2 & 3.8 & 3.4 \\
\hline
\end{tabular}

Table 2: Responses to the questions related to the disadvantages of group work

\begin{tabular}{lcccc}
\hline \multirow{2}{*}{ Responses } & \multicolumn{4}{c}{ Percentage (\%) } \\
\cline { 2 - 5 } & $\begin{array}{c}\text { Lack of time management } \\
\text { and delay }\end{array}$ & $\begin{array}{c}\text { Unfair distribution of } \\
\text { marks }\end{array}$ & $\begin{array}{c}\text { Non-cooperation } \\
\text { Free riding }\end{array}$ \\
\cline { 2 - 5 } Strongly agree & 29.2 & 28.0 & 14.5 & 30.3 \\
Agree & 49.6 & 39.4 & 31.3 & 32.2 \\
Neither agree nor disagree & 16.7 & 23.9 & 34.7 & 20.7 \\
Disagree & 1.5 & 3.4 & 9.9 & 9.2 \\
Strongly disagree & 3.0 & 5.3 & 9.5 & 7.7
\end{tabular}

Similarly, the disadvantages of group assignments according to student responses in the pilot study include 1) lack of time management and delay from members, 2) unfair distribution of marks, 3) non-cooperation of certain members, and 4) free riding. Interestingly, these findings do validate the evidences from current literature. An analysis of disadvantages based on the second study shows that $78.8 \%$ of participants agree that the time management and delay from peers are one of the biggest challenges of group works. $67.4 \%$ of respondents agree that the group works lead to unfair distribution of grades if the marks are awarded regardless of the individual contribution. Almost half of the participants (45.8\%) admit that the non-cooperation of few group members creates problems, and $62.5 \%$ of participants agree free riding is inevitable in group works. Following table 2 summarises the responses on the disadvantages of group works.

\section{Capturing individual contribution and peer evaluation}

As mentioned under literature review section, various literatures on group work deal with the problems of free riding and necessity of capturing individual contribution while awarding grades.

Several studies also shed lights on the concept of peer evaluation to alleviate the free riding and ensure fairer marks distribution. In an attempt to get the student perception on these areas, two questions were added regarding the marks distribution based on the individual contribution and adopting the practices of peer evaluation.

The analysis shows that $54.4 \%$ of the participants favour the idea of marks allocation based on the individual contribution, and the rest prefer marks to be distributed equally among all members of the group. Further analysis made to see the differences in the response based on the academic performance of students gives an interesting finding as $75.3 \%$ of students with higher CGPA prefer the marks distribution should consider the individual contribution of group members, whereas only $43.8 \%$ of the students with lower CGPA prefer the same. The difference is found to be significant with a p-value of 0.000 .

Peer evaluation is favoured by most of the participants $(76.4 \%)$. Independent sample t-tests were conducted to find out if there is a difference in participants' preference on peer evaluation based on 1) academic performance, 2 ) levels and 3 ) relative preference on marks distribution. The results show that the responses are similar among the groups compared, and there is no significant difference between them. This implies that the peer evaluation is preferred by most of the participants regardless of their academic performance, levels and the relative preference on marks distribution. 
Refeque et al. 039

Table 3: Strategies followed by the participants to make others work

\author{
Having frequent meetings and communications \\ Having one group leader to coordinate \\ Educating the students about the importance of the assignments and grades \\ Distributing workloads fairly and assigning timeline \\ Respecting the ideas from others and being the part of team \\ Motivating the students to be more serious and responsible \\ Clearly communicating the individual tasks and responsibilities \\ Reminding them about their potential \\ Having continuous follow ups and involvement in the group
}

\section{Strategies and technologies}

In an attempt to know the strategy that could be followed in group projects, questions were included on preferred task completion strategy employed to complete the given task, and it is found that $64.6 \%$ of students prefer to divide the tasks among the group members and $35.4 \%$ of students prefer to complete all the tasks in groups. $60.6 \%$ of students with lower CGPA and $75.6 \%$ of them with higher CGPA prefer dividing the tasks between group members $(p$-value $=0.049$ ).

Similarly, this study also identified some of the mechanisms adopted by students to make the group members work. Out of 274 of such responses, most repeated ones are captured in table 3 above. The responses indicate that, in order to accomplish group targets, the students use different skills and strategies varying from taking leadership and motivational initiatives to having regular communications and follow-up mechanisms.

Communication between the group members is one of the critical success factors for effective accomplishments of group project. There are generally many ways and technologies used by students in order to facilitate the communication between the group members. The study found that WhatsApp is most preferred channel of communication $(80.1 \%)$ followed by E-mail $(15.3 \%)$ and Moodle (4.6\%).

\section{CONCLUSION AND RECOMMENDATIONS}

An inquiry into the students' perception of group work provided many insights related to its management, advantages and disadvantages accrue group works, and marks allocation. Contrary to anecdotal belief that the students dislike group works, study found that the preferences between individual and group works are not significantly different. However, the preference for individual assignment is positively related to academic performance and semester of study. Preference for individual assignment by the students with higher CGPA and those in the higher semester implies that the students are getting more aware about the problems of free riding and unfair marks distribution, as the marks do not reflect individual contribution. Educators have to make sure that the spirit of group works are carried by the students throughout the period of their studies.

Generally, all the participants want the tasks to be divided between the members rather than completing all the tasks in groups. This trend is more popular among students with higher CGPA. Teachers have to encourage and facilitate the fair distribution of tasks between the group members in order for the students to have a positive group work experience.

In line with the existing literature, the study found that the group assignments have many advantages and disadvantages. According to the students surveyed, the most important advantages are knowledge co-creation, acquisition of generic skills, especially communication and teamwork skills. The disadvantages are lack of responsibility and non-cooperation of certain group members, free riding and unfair mark distribution. As the educational institutions try to provide a better learning experience to students through various assessments, diligent care needs to be taken to maximise the benefits and minimise the demerits associated with group works.

One of the strong recommendations this study could place on record is the need for differentiating the group work grades based on the individual contribution. Students, irrespective of their academic performance and semester, prefer to have a fair mechanism in place to consider individual contribution for marks allocation. It is worth mentioning that such preference is found to be more among the students with strong academic performance. In this regard, peer evaluation is valued by a good majority of students as a means to fairly differentiate the grades for group work based on the individual efforts. However, further research needs to be conducted to understand the impacts of peer evaluation on marks distribution and subsequent perception of students.

As a community of learners, while working in groups, students adopt a wide variety of strategies to ensure the 
contribution of all members. The analysis of their responses shows that the successful accomplishment of group objectives requires adoption of many strategies, such as effective communication and follow-up mechanisms, taking leadership and motivational roles, encouraging continuous involvement with the members and ensuring clear distribution of responsibilities.

The current study added value to existing literature and achieved its intended objectives in terms of capturing students' perception of group works. Study asserts that the group works play an important role in enhancing students' learning experience and contributing to their overall development.

Further research can be conducted covering other specialisations as this study surveyed only the undergraduate students majoring in business administration. However, as the students generally possess common characteristics, the findings of the study can also be extended to other specialisations.

\section{REFERENCES}

Abele S, Diehl M (2008). Finding teammates who are not prone to sucker and free-rider effects: The protestant work ethic as a moderator of motivation losses in group performance. Group Processes and Intergroup Relations11(1), 39-54.

Aggarwal P, O'Brien CL (2008). Social loafing on group projects: Structural antecedents and effect on student satisfaction. J. Marketing Edu. 30(3), 255-264.

Alden J (2011). Assessment of Individual Student Performance in Online Team Projects. J. Asynchronous Learning Networks15(3), 520.

Amato $\mathrm{CH}$, Amato LH (2005). Enhancing student team effectiveness: Application of Myers-Briggs personality assessment in business courses. J. Marketing Education 27(1), 41-51.

Beebe SA, Masterson JT (2003). Communicating in Small Groups. Boston: Pearson Education Inc.

Bentley Y, Warwick S (2013). Students' experience and perceptions of group assignments. Journal of Pedagogic Development 3(3), 11-19.

Börjesson PO, Hamidian A, Kubilinskas E, Richter U, Weyns K, Ödling $P$ (2006). Free-riding in group work-mechanisms and countermeasures. In: $4^{\text {th }}$ Pedagogiskalnspirationskonferensen, Lund., $1^{\text {st }}$ June 2006, Retrieved from https://www.Ith.se/fileadmin Ith/genombrottet/konferens2006/p o b riesson mfl.pdf (accessed 20 February 2017).

Brooks CM, Ammons JL (2003). Free riding in group projects and the effects of timing, frequency, and specificity of criteria in peer assessments. J. Education for Business 78(5), 268-272.

Burke A (2011), Group Work: How to Use Groups Effectively. Journal of Effective

Butcher AC, Stefani LAJ, Tariq VN (1995). Analysis of peer-, self-and staff-assessment in group project work. Assessment in Education: Principles, Policy and Practice2(2), 165-185.

Cheng W, Warren M (2000). Making a difference: Using peers to assess individual students' contributions to a group project. Teaching in Higher Edu. 5(2), 243-255.

Colbeck CL, Campbell SE, Bjorklund SA (2000). Grouping in the dark: What college students learn from group projects? The Journal of Higher Education 71(1), 60-83.

Elliott N, Higgins A (2005). Self and peer assessment-does it make a difference to student group work? Nurse Education in Practice 5(1), 40-48.

Friedman BA, Cox PL, Maher LE (2008). An expectancy theory motivation approach to peer assessment. J. Management Edu. 32(5), 580-612.
Gamson ZF (1994). Collaborative learning comes of age. Change: The Magazine of Higher Learning 26(5), 44-49.

Garvin JW, Butcher AC, Stefani LAJ, Tariq VN, Lewis MHR, Blumson NL, Govier RN, Hill JA (1995). Group projects for first-year university students: an evaluation. Assessment and Evaluation in Higher Education 20(3), 273-288.

Gibbs G (2009). The assessment of group work: lessons from the literature. Assessment Standards Knowledge Exchange. Centre for Excellence in Teaching and Learning in Higher Education, The Business School, Oxford Brookes University.

Hall D, Buzwell S (2013). The problem of free-riding in group projects: Looking beyond social loafing as reason for non-contribution. Active Learning in Higher Education 14(1), 37-49.

Hansen RS (2006). Benefits and problems with student teams: Suggestions for improving team projects. J. Education for Business 82(1), 11-19.

Harkins SG, Latane B, Williams K (1980). Social loafing: Allocating effort or taking it easy? J. Experimental Social Psychology 16(5), 457-465

Hayes JH, Lethbridge TC, Port D (2003). Evaluating individual contribution toward group software engineering projects. In: 25th international conference on software engineering, Portland, USA, 310 May 2003, pp. 622-627). IEEE Computer Society.

Johnson DW (1991). Cooperative Learning: Increasing College Faculty Instructional Productivity. ASHE-ERIC Higher Education Report no. 4, George Washington University, One Dupont Circle, Suite 630, Washington, DC 20036-1183.

Kennedy GJ (2005). January Peer-assessment in group projects: is it worth it? In: 7th Australasian conference on computing education (eds A Young and D Tolhurst), Australian Computer Society, Inc.

Kerr NL (1983). Motivation losses in small groups: A social dilemma analysis. J. Personality and Social Psychology 45(4), 819.

Kerr NL, Bruun SE (1983). Dispensability of member effort and group motivation losses: Free-rider effects. J. Personality and Social Psychology 44(1),78-94.

Knight J (2004). Comparison of student perception and performance in individual and group assessments in practical classes. Journal of Geography in Higher Education 28(1), 63-81.

Kruck SE, Reif HL (2001). Assessing individual student performance in collaborative projects: A case study. Information Technology, Learning, and Performance J. 19(2), 37

Latané B, Williams K, Harkins S (1979). Many hands make light the work: The causes and consequences of social loafing. J. Personality and Social Psychology 37(6), 822.

Li M, Campbell J (2008). Asian students' perceptions of group work and group assignments in a New Zealand tertiary institution. Intercultural Edu. 19(3), 203-216.

Maiden B, Perry B (2011). Dealing with free-riders in assessed group work: results from a study at a UK university. Assessment and Evaluation in Higher Education 36(4), 451-464.

Mathews BP (1994). Assessing individual contributions: Experience of peer evaluation in major group projects. British J. Educational Technology 25(1), 19-28.

McArdle G, Clements KD, Hutchinson-Lendi K (2005). The free rider and cooperative learning groups: perspectives from faculty members. In: $12^{\text {th }}$ academy of human resource development international conference, Estes Park, USA, 24-27 February 2005, pp.529-535.

Morris R, Hayes C (1997). Small group work: Are group assignments a legitimate form of assessment. Learning through Teaching Feb, 229-233.

Mulvey PW, Klein HJ (1998). The impact of perceived loafing and collective efficacy on group goal processes and group performance. Organizational Behavior and Human Decision Processes 74, 62-87.

Pfaff E, Huddleston P (2003). Does it matter if I hate teamwork? What impacts student attitudes toward teamwork. J. Marketing Edu. 25(1), 37-45.

Piezon SL, Donaldson RL (2005). Online groups and social loafing: Understanding student-group interactions. Online J. Distance Learning Administration 8(4), 1.

Raban R, Litchfield A (2007). Supporting peer assessment of individual 
contributions in groupwork. Australasian J. Educational Technology 23(1), 34-47.

Robbins TL (1995). Social loafing on cognitive tasks: An examination of the "sucker effect". Journal of Business and Psychology9(3), 337342.

Ruel GC, Bastiaans N, Nauta A (2003). Free-riding and team performance in project education.

Smith C, Bath D (2006). The role of the learning community in the development of discipline knowledge and generic graduate outcomes. Higher Education51(2), 259-286.

So HJ, Brush TA (2008). Student perceptions of collaborative learning, social presence and satisfaction in a blended learning environment: Relationships and critical factors. Computers and Education 51(1), 318-336.

Stroebe W, Diehl M, Abakoumkin G (1996). Social compensation and the Köhler effect: Toward a theoretical explanation of motivation gains in group productivity. Understanding Group Behavior2, 37-65.

Teaching 11(2), 87-95.

Topping K (1998). Peer assessment between students in colleges and universities. Review of Educational Res. 68(3), 249-276.

Van Zundert M, Sluijsmans D, Van Merriënboer J (2010). Effective peer assessment processes: Research findings and future directions. Learning and Instruction 20(4), 270-279.
Waite WM, Jackson MH, Diwan A, Leonardi PM (2004). Student culture vs. group work in computer science. ACM SIGCSE Bulletin 36(1), 12-16.

Webb NM (1995). Group collaboration in assessment: Multiple objectives, processes, and outcomes. Educational Evaluation and Policy Analysis 17(2), 239-261.

Wilkins DE, Lawhead PB (2000). Evaluating individuals in team projects. ACM SIGCSE Bulletin 32(1), 172-175.

Williams K, Harkins SG, Latané B (1981). Identifiability as a deterrant to social loafing: Two cheering experiments. J. Personality and Social Psychology 40(2), 303. 